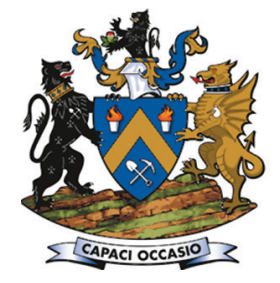

Affiliation:

${ }^{1}$ Centre for Pyrometallurgy,

Department of Materials Science and Metallurgical Engineering,

University of Pretoria.

Correspondence to:

A.M. Garbers-Craig

Email:

Andrie.Garbers-Craig@up.ac.za

Dates:

Received: 30 Nov. 2019

Revised: 22 Jun. 2020

Accepted: 23 Jun. 2020

Published: June 2020

How to cite:

Steenkamp, H. and

Garbers-Craig, A.M.

An investigation into the

permeability of a PGM slag freeze

lining to sulphur.

The Southern African Insitute of

Mining and Metallurgy

DOI ID:

http://dx.doi.org/10.17159/2411$9717 / 1044 / 2020$

\section{An investigation into the permeability of a PGM slag freeze lining to sulphur}

\author{
H. Steenkamp ${ }^{{ }^{*}}$ and A.M. Garbers-Craig1 \\ *Paper written on project work carried out in partial fulfilment of B.Eng \\ (Metallurgy) degree
}

\section{Synopsis}

Sulphur driven off from the sulphides in the black top of PGM smelters has in past years caused failure of copper coolers. When the magnesia-chromite bricks in the smelter were replaced with graphite blocks, however, copper cooler corrosion drastically decreased and furnace campaign lives improved. This study explores the role of the slag freeze lining in the permeation of sulphur to the copper cooler. This was done by measuring the gas permeabilities of two freeze linings and comparing them against the permeabilities of typical graphite and magnesia-chromite bricks that are used in PGM smelters; measuring the gas permeabilities of the different layers (hot face, crystalline layers, and cold face) of a freeze lining; and testing the permeation of liquid sulphur through freeze lining samples at 120 and $180^{\circ} \mathrm{C}$. It was found that the freeze lining samples had gas permeabilities of 1.5 and $0.8 \mathrm{~cd}$ at a differential pressure of 32 $\mathrm{kPa}$, compared to the permeabilities of the magnesia-chromite $(10.0 \mathrm{~cd})$ and graphite bricks $(4.85 \mathrm{~cd})$. The cold face layer of the freeze lining had the lowest permeability $(1.8 \mathrm{~cd})$, and the hot face layer the highest $(2.4 \mathrm{~cd})$. At $120^{\circ} \mathrm{C}$ liquid sulphur permeated the freeze lining through cracks. The freeze lining can therefore participate in preventing sulphur permeation towards the copper coolers, as long as its cold face remains intact and crack free. An added benefit of using graphite blocks in the smelter is that it establishes a glassy cold face layer in the freeze lining, which has a very low gas permeability.

\section{Keywords}

slag freeze lining, permeability, sulphidation of copper coolers, porosity.

\section{Introduction}

Copper coolers used in the primary smelting furnaces of the platinum group metal (PGM) industry fail due to chloride-accelerated sulphidation (Shaw et al., 2013). This is caused by sulphur being driven off from sulphides in the green concentrate which, together with chlorine-bearing species in the presence of moisture, diffuses towards the copper cooler and reacts with it. The corrosion rate and morphology of the corrosion products that form on the copper coolers are functions of temperature and corrosive gas composition $\left(\mathrm{H}_{2} \mathrm{~S}, \mathrm{~S}_{2}\right.$, and a combination of $\mathrm{S}_{2}$ and $\mathrm{HCl}$ ) (Thethwayo and Garbers-Craig, 2011, 2010). $\mathrm{HCl}$ was found to significantly increase the rate of sulphidation of the copper coolers at temperatures as low as $90^{\circ} \mathrm{C}$.

The PGM slag freeze lining has a porous appearance which creates the expectation that it does not play a role in the prevention of sulphur migration to the copper coolers. Against this background, the purpose of this study was to determine what role the slag freeze lining plays in the migration of sulphur from the molten bath to the copper coolers. The research had three objectives: to determine the gas permeability of the freeze lining and to compare it to the permeabilities of refractory bricks used in the PGM industry; to determine which layer of the freeze lining (hot face, crystalline layers, or cold face) has the lowest gas permeability; and to determine the permeability of a PGM freeze lining to liquid sulphur.

The slag freeze lining samples that were investigated were taken from two primary PGM smelters owned by Anglo American Platinum in South Africa.

\section{Background}

\section{PGM smelting and the use of copper coolers}

Anglo American Platinum treats sulphide ores from three reefs within the Bushveld Complex, namely the Merensky, UG2, and Platreef (Jacobs, 2006). The ore is crushed and the base metal sulphides with which the PGMs are associated are upgraded through sulphide flotation. The concentrate is then smelted 


\section{An investigation into the permeability of a PGM slag freeze lining to sulphur}

to allow for separation of the gangue and sulphides into slag and matte respectively, based on their different densities. In South Africa Anglo American Platinum has its smelting operations at the Waterval, Mortimer, and Polokwane plants (Hundermark et al., 2011). After smelting, the furnace matte is further processed in a converter to remove iron and sulphur, after which the respective base metals and PGMs are separated into saleable products.

Copper coolers were first implemented in the furnace linings of PGM smelters in 1990. This allowed for a high enough heat flux to be generated across the furnace wall whereby a layer of molten slag could freeze onto the hot face of the refractory bricks in contact with the copper cooler, creating a freeze lining. The freeze lining protects the underlying refractory lining from chemical attack by slag, erosion, and thermal stress (Duncanson and Toth, 2004). Before freeze linings were used, furnace walls had to be rebuilt every two to three years, whereas the expected lives of the copper coolers are measured in decades (Shaw et al., 2013).

Corrosion of the furnace lining became a major issue in the Anglo American Polokwane Smelter when the shift from the plate copper cooler design to the waffle copper cooler design was implemented (Shaw et al., 2013). The greater efficiency of the waffle copper cooler facilitated a significant increase in furnace power input (from 34-42 MW to $68 \mathrm{MW}$ ). However, a new wear mechanism, the corrosion of the hot face of the copper coolers in the upper slag zone, led to a shortened campaign life of the waffle coolers (Figure 1). Since the cooling medium in the copper coolers is water, damage to the water channels led to a water leak and a subsequent steam explosion. Explosions can cause failure of the furnace wall, run-out of molten material, major infrastructural damage, and significant downtime of the furnace. Fatalities and injuries to personnel working in close vicinity of the furnace can also result.

According to Shaw et al. (2013) there was an abundance of elemental sulphur at the corroded hot face of the copper cooler removed from the Polokwane Smelter in 2004. The presence of sulphur was not a surprise as the base metal sulphide concentrate charged into the furnace was not roasted to remove sulphur before smelting, as in other sulphide smelting industries. Thermal decomposition of sulphides in the concentrate ('black top') and matte therefore occurs in the smelter, whereby sulphur is produced according to Equations [1] to [5] (Thethwayo, 2010; Mabiza et al., 2011):

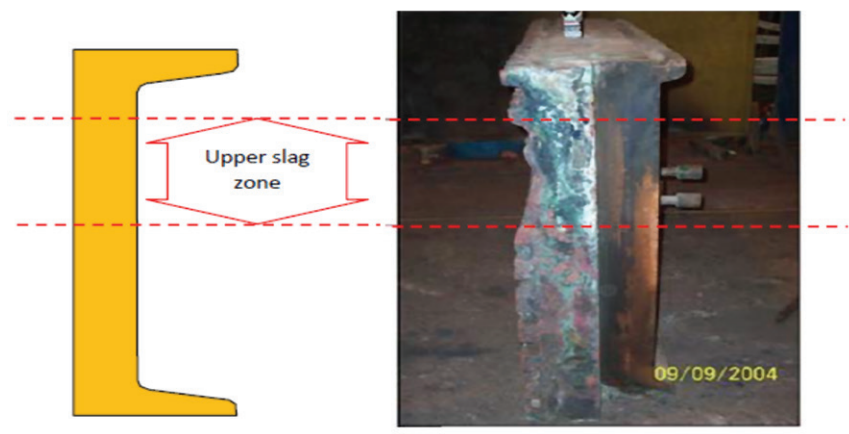

Figure 1-Corrosion of the copper cooler, characterized by the presence of copper sulphide in the upper slag zone close to the slag-concentrate interface (after Shaw et al., 2013)

$$
\begin{aligned}
& 5 \mathrm{CuFeS}_{2}(\mathrm{~s}) \rightarrow 4 \mathrm{FeS}(\mathrm{l})+\mathrm{Cu}_{5} \mathrm{FeS}_{4}(\mathrm{l})+\mathrm{S}_{2}(\mathrm{~g}) \\
& \mathrm{Ni}_{9} \mathrm{Fe}_{8} \mathrm{~S}_{15} \rightarrow 3 \mathrm{Ni}_{3} \mathrm{~S}_{2}+8 \mathrm{FeS}+1 / 2 \mathrm{~S}_{2}(\mathrm{~g}) \\
& \mathrm{Fe}_{7} \mathrm{~S}_{8} \rightarrow 7 \mathrm{FeS}+1 / 2 \mathrm{~S}_{2}(\mathrm{~g}) \\
& \mathrm{FeS}_{2}(\mathrm{~s}) \rightarrow \mathrm{FeS}(\mathrm{l})+1 / 2 \mathrm{~S}_{2}(\mathrm{~g}) \\
& 3 \mathrm{NiS}(\mathrm{s}) \rightarrow \mathrm{Ni}_{3} \mathrm{~S}_{2}+1 / 2 \mathrm{~S}_{2}(\mathrm{~g})
\end{aligned}
$$

The corrosion products that formed at the hot face of the Polokwane copper cooler in 2004 were identified using EDS analysis. The various product layers are illustrated in Figure 2.

Shaw et al. (2013) reported that water-cooled copper can react with sulphur gas at temperatures as low as $25^{\circ} \mathrm{C}$, while the presence of $\mathrm{HCl}$ gas greatly accelerates corrosion of the copper coolers. The corrosion mechanism was described as 'chlorideaccelerated sulphidation', as it involves the corrosion of copper in the presence of sulphur- and chlorine-bearing species in the presence of moisture (Shaw et al., 2013).

Measures that have been taken to monitor chlorideaccelerated sulphidation include ultrasonic measurement of the thickness of the corrosion layer on the copper coolers and detection of water leaks which may be a result of copper cooler corrosion (Shaw et al., 2013). Downtime during copper cooler replacement was shortened by separating the copper cooler into an upper and lower cooler, whereby the upper cooler could be replaced separately, requiring only partial drainage of the furnace. Corrosion layers do not protect the copper as the corrosion products have Pilling-Bedworth ratios of more than two (Shaw et al., 2013). The corrosion products therefore flake off, exposing fresh copper and corrosion continues. Post-mortem analyses of magnesia-chromite and graphite bricks removed from PGM smelters confirmed that the refractory bricks together with the rammable (which ensures thermal contact between the refractory brick and the copper cooler) do not keep the sulphide corrosion product secured to the copper (Thethwayo and Garbers-Craig, 2010). Visual inspection of the magnesia-chromite lined smelter wall also indicated that the brick at the concentrate-slag interface was completely corroded away, leaving the freeze lining in direct

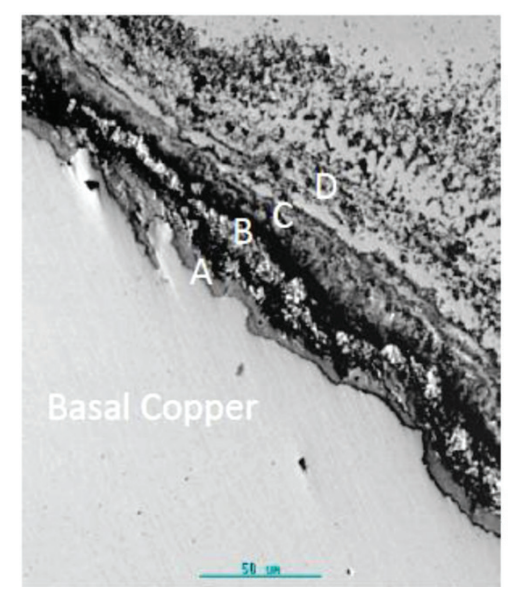

Figure 2-Backscatter electron image of the corrosion layers (A, B, C and D) at the interface of the 2004 Polokwane copper cooler. Layers C and D consisted mainly of copper sulphides. Layer B consisted of oxygen-bearing copper sulphides, chlorides, and sulphates. In direct contact with the basal copper (layer A) was a thin layer of copper chloride (after Shaw et al., 2013) 


\section{An investigation into the permeability of a PGM slag freeze lining to sulphur}

contact with the copper cooler. Magnesia-chromite bricks that were used in contact with the copper coolers were subsequently replaced with graphite blocks. The use of graphite-protected copper coolers in the concentrate-slag zone has significantly slowed the rate of copper cooler corrosion and drastically improved furnace campaign life (Shaw et al., 2013).

The sulphur partial pressure in the smelter is a function of the sulphur content of the matte and the temperature (du Preez, 2009). If the PGM matte with a sulphur content of $22-30 \mathrm{wt} \%$ (Nolet, 2014) is assumed to behave like nickel matte, the sulphur partial pressure at the slag-concentrate interface in front of the hot face of the freeze lining will range between $10^{-5}$ and $10^{-4}$ atm. at $1400^{\circ} \mathrm{C}$ (Figure 3, du Preez, 2009). From the $\log \mathrm{P}_{\mathrm{S}_{2}}{ }^{-}$ temperature diagram published by Lyons (2008), it is clear that sulphur partial pressure above $10^{-5} \mathrm{~atm}$. can be achieved when heating sulphur (S8) at temperatures above $100^{\circ} \mathrm{C}$ (Figure 3).

\section{Microstructures of freeze linings}

There are many factors that control the microstructural characteristics of a freeze lining. According to Crivits (2016) the efficiency of a freeze lining is best when the initial solidification is dominated by the rapid growth of interlocking crystals and the formation of a subsequent high-melting crystalline sealing layer.

Three major layers are discerned: the cold face adjacent to the refractory brick, the hot face in contact with the slag bath, and a series of crystalline layers in-between the cold and hot faces. The layers in a $\mathrm{PbO}-\mathrm{ZnO}-\mathrm{FeO}-\mathrm{Fe}_{2} \mathrm{O}_{3}-\mathrm{CaO}-\mathrm{SiO}_{2}$-based freeze lining produced in laboratory experiments were identified and classified by Crivits (2016) in terms of their microstructures and compositions (Figure 4). The first two layers that formed on a cold finger probe were glassy in nature and are referred to as the 'cold face'.

The cold face consists of an amorphous phase with a homogeneous composition identical to that of the slag bath, followed by a glassy layer, which contains very fine crystals. The next few layers form part of the group of crystalline layers of the freeze lining. The first crystalline layer is the "closed crystalline layer', which consists of crystals that solidified directly from the melt and that effectively prevented the exchange of molten material between the bath and the freeze lining. The 'open crystalline layer' consists of large crystalline grains with a significant liquid fraction that is open for exchange of material with the slag bath. The last major layer is the 'hot face', which is a sub-liquidus layer that forms the interface between the freeze lining and the molten bath. It has a higher porosity than the dense cold face and an irregular surface. This sealing layer wconsists of primary crystals that continuously precipitate and dissolve directly from the bath. Crivits (2016) found that a thin layer of slag from the bulk slag bath formed the outer layer of the freeze lining (layer 6, Figure 4). The major layers, namely the cold face, crystalline layers, and hot face, are expected to have different gas permeabilities due to their different microstructures.

\section{Theory of permeability}

In this study, the permeability of a PGM slag freeze lining and other refractory materials were investigated as a measure of the ease with which sulphur can migrate towards the copper coolers. Permeability refers to the capacity of a porous material for transmitting a fluid (liquid or gas); it is expressed as the velocity with which a fluid of specified viscosity, under the influence of a given pressure, passes through a sample having a certain cross-section and thickness (Augustyn, et al., 2018). Apparent porosity is the volume of open pores as a percentage of the bulk volume of a material and can be used to compare the expected corrosion resistance of different materials (Berger, 2010). A direct relationship between permeability and apparent porosity does not exist, as only connected open pores affect permeability and facilitate permeation of fluids through a material.

The ASTM Permeability Test Method C577-07 is used to measure the permeability of refractory bricks. The permeability is calculated according to Darcy's Law (Equation [6]):

$$
K=\frac{M Q L}{A \Delta P} \times 100
$$
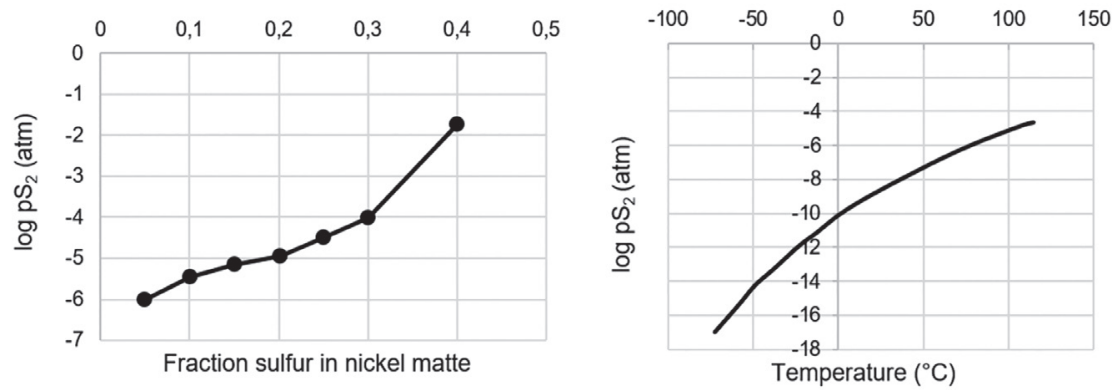

Figure 3-(Left) The partial pressure of sulphur as a function of the sulphur content of a nickel-based matte (after du Preez, 2009); (right) the partial pressure of sulphur $\left(\mathrm{S}_{8}\right)$ as a function of temperature (after Lyons, 2008)

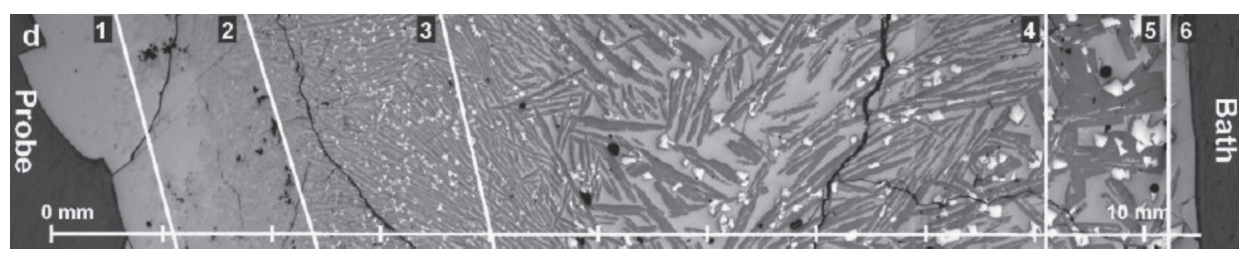

Figure 4-Cross-section of a freeze lining that formed from a $\mathrm{PbO}-\mathrm{ZnO}-\mathrm{FeO}-\mathrm{Fe}_{2} \mathrm{O}_{3}-\mathrm{CaO}-\mathrm{SiO}_{2}$ slag on a cold finger probe, submergence time 120 min. (1) Glassy layer, (2) glass with fine crystals, (3) closed crystalline layer, (4) open crystalline layer, (5) layer of sealing crystals, (6) layer of entrained slag from slag bath (after Crivits, 2016) 


\section{An investigation into the permeability of a PGM slag freeze lining to sulphur}

where

$K$ : permeability, centidarcys

$M$ : gas or liquid viscosity, $\mathrm{CP}$ (temperature- dependent)

Q: flow rate, $\mathrm{cm}^{3} / \mathrm{s}$

$L$ : sample length, cm

$A$ : sample area, $\mathrm{cm}^{2}$

$\Delta P$ : absolute pressure drop across the sample, atm.

The permeability is expressed in darcys, where 1 darcy is equal to $10^{-12} \mathrm{~m}^{2}$. One centidarcy is a flow of $0.01 \mathrm{~cm}^{3} / \mathrm{s}$ of a fluid of $1 \mathrm{cP}$ viscosity through a $1 \mathrm{~cm}$ cube under a pressure difference of $1 \mathrm{~atm}$. The ASTM standard stipulates that the permeability be reported at a pressure differential of $32 \mathrm{kPa}$. Permeabilities at lower and higher pressure differentials were also measured in this study.

The permeability of a material constituted from a number of layers can be calculated from the permeabilities and thicknesses of the layers according to Equation [7] (Kantzas, Bryan, and Taheri, 2015). This calculated overall permeability of the material is called the harmonic-average permeability. For steady state, the flow rate through each layer is the same and the pressure drop across the entire system is therefore the sum of the pressure drops across each layer (Equation [8]).

$$
K_{a v}=\frac{L}{\left(\frac{L}{K}\right)_{1}+\left(\frac{L}{K}\right)_{2}+\left(\frac{L}{K}\right)_{3}}
$$

where

$$
\Delta P_{t}=\Delta P_{1}+\Delta P_{2}+\Delta P_{3}
$$

$K_{a v}=$ harmonic-average permeability

$L=$ total thickness of the multi-layered material

$(L / K)_{i}=$ thickness to permeability ratio of layer $i$

$\Delta P_{t}=$ pressure drop across the multi-layered material

$\Delta P_{i}=$ pressure drop across layer $i$

In this study the harmonic-average permeability of the Mortimer freeze lining was calculated from the individually measured permeabilities and thicknesses of the cold face, crystalline, and hot face layers of the freeze lining.

\section{Experimental}

\section{Sampling}

Freeze lining samples were taken in 2018 and 2019 from the Anglo American Platinum Polokwane and Mortimer smelters respectively (Figure 5). These samples were taken from the sidewall at the slag-concentrate interface level, as this was the location of wear of the copper coolers (Figure 1). The morphology of the freeze lining is dependent on the conditions inside the furnace and may vary considerably over time. The Polokwane freeze lining sample was thinner than the Mortimer freeze lining sample $(8 \mathrm{~cm} v S .10 \mathrm{~cm}$ from the cold face to the hot face) and seemed less porous to the naked eye.

Magnesia-chromite and graphite bricks, typically used in the PGM smelters, were obtained from Anglo American Technical Solutions (at Crown Mines) in order to compare the permeabilities of the bricks with the freeze lining in the PGM smelter lining (Figure 6).

\section{Bulk density and apparent porosity measurements}

The bulk densities and apparent porosities of the freeze lining and brick samples were determined at Cermalab Materials Testing
Laboratory. The measurements were carried out according to the ISO 5016, ASTM C134, and ASTM D1895 test methods (Berger, 2010).

\section{Sulphur penetration into the freeze lining}

The Polokwane freeze lining sample was sectioned from the cold face to the hot face, whereby a $8 \mathrm{~cm}$ long and $3.5 \mathrm{~cm}$ wide sub-sample was taken for the sulphur penetration experiments. This $8 \mathrm{~cm}$ long sample was further sectioned in half through the crystalline layer, resulting in a top section (containing the hot face and part of the crystalline layer) and a bottom section (containing the rest of the crystalline layer and the cold face). In the first experiment a piece of sulphur was placed on top of the hot face of the top section, and on top of the crystalline face of the bottom section. Each freeze lining sample with the piece of sulphur was placed inside a graphite crucible, which in turn was placed inside a steel capsule. The capsule was then purged with argon, sealed (by welding a steel end cap onto the capsule and welding the perimeter of the purge screw) and placed in an autoclave. These assemblages were heated to $120^{\circ} \mathrm{C}$ and $180^{\circ} \mathrm{C}$ respectively and kept at the elevated temperature for 6 hours. These two temperatures were chosen so as to ensure that the sulphur was molten at the reaction temperature (melting point of sulphur is $115^{\circ} \mathrm{C}$; Bello, 1988) and that the sulphur partial pressure was maintained above $10^{-5} \mathrm{~atm}$. (Figure 3 , Lyons, 2008). The temperature was monitored with a K-type thermocouple wrapped around the steel capsule. The sulphur melted and accumulated at the bottom of the crucible without penetrating the freeze lining.

For the next set of experiments $5 \mathrm{~mm}$ holes were drilled into the freeze lining specimens: through the hot face and partly into the crystalline layers, for the top section, and through the rest of
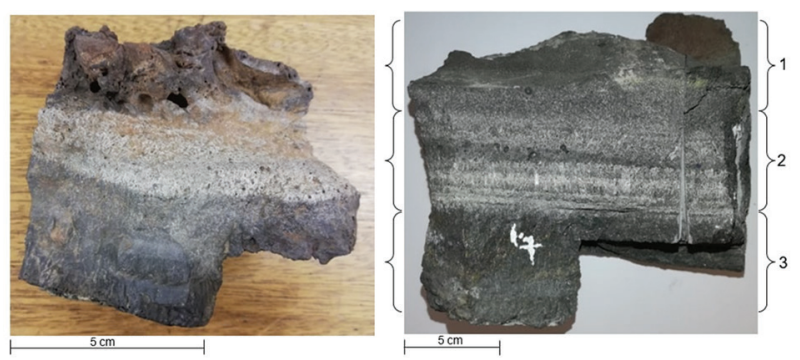

Figure 5-Photographs of the freeze lining samples retrieved from Polokwane Smelter in 2018 (left) and Mortimer Smelter in 2019 (right), with 1,2 , and 3 annotating the hot face, crystalline layer group, and cold face

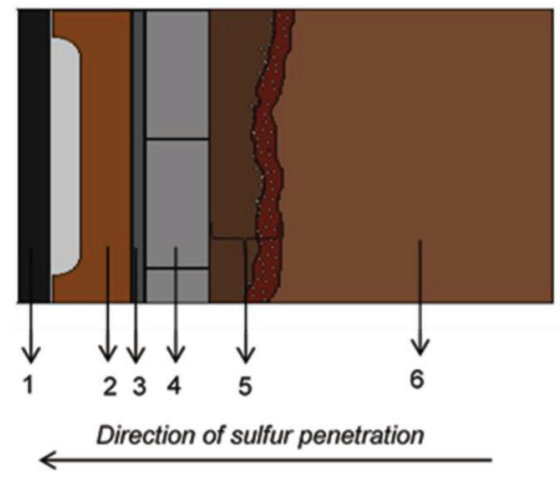

Figure 6-Schematic diagram of a section through the sidewall of a PGM smelter: (1) steel shell, (2) copper cooler, (3) ramming paste, (4) refractory brick layer, (5) freeze lining, and (6) molten slag bath 


\section{An investigation into the permeability of a PGM slag freeze lining to sulphur}

the crystalline layer and partly into the cold face of the bottom section of the freeze lining specimen. The holes were filled with pulverized sulphur to determine whether sulphur would permeate into the freeze lining if the low wettability of sulphur on the freeze lining was overcome (Figure 7). The depth of penetration of sulphur into the freeze lining at the two temperatures was evaluated by examining a cross-section through the sulphur-filled specimen using SEM-EDS.

\section{Permeability measurements}

A permeability apparatus was constructed by adapting the ASTM C577-07 permeability test method to facilitate testing the freeze lining specimens as well as the refractory brick specimens (Figure 8).

The pressure drop across a specimen was measured with a Panasonic ADP 5140 gauge pressure sensor. The pressure sensor was connected to an Arduino UNO microcontroller board. The Arduino allowed the amplification of the output signal from the pressure sensor, which ranged from zero to five volts, to $\mathrm{kPa}$. The amplification parameters were determined by calibration: a pressure was applied to both the pressure sensor and a U-tube manometer filled with mercury; the pressure was increased in increments and the level of the mercury in the manometer and the output voltage from the sensor recorded. The amplification parameters derived from the original pressure sensor output are stipulated in Equation [9]. Figure 9 shows the linear correlation between the output voltage and the pressure derived from the mercury manometer after calibration.

$$
V=0.0375 P+0.6033
$$

$V:$ pressure sensor output in volts

$P$ : pressure derived from mercury level in manometer

The ASTM standard recommends the use of a rubber gasket with a square aperture to seal off the edges of the sample during

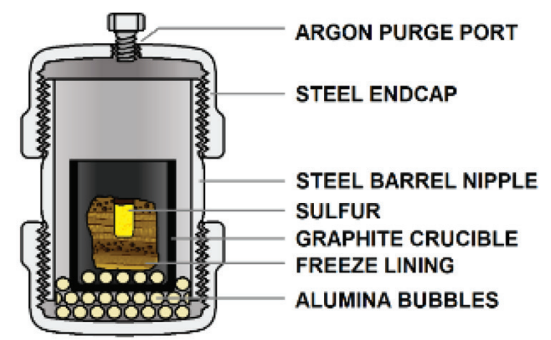

Figure 7-Test capsule with freeze lining filled with pulverized sulphur

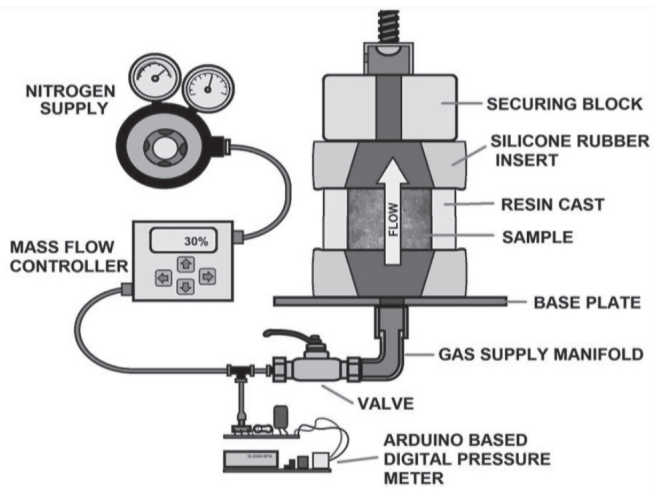

Figure 8-The permeability apparatus that was constructed according to the ASTM C577-07 standard the permeability measurement. Although a square shaped aperture worked well when measuring the permeability of a refractory brick that can easily be sectioned into a cube, this was not the case with the freeze lining. The freeze lining had irregular faces and was brittle. This made it difficult to cut a sample into a regular shape such as a cube. To accommodate the uneven faces of the freeze lining, the method was adapted from the ASTM standard and samples were set in resin (to allow for sealing of the irregular edges of the freeze lining) and two silicone gaskets were made to seal onto the top and bottom surfaces of the resin (Figure 10).

Cubic specimens measuring $5.08 \times 5.08 \mathrm{~cm}^{2}\left(2 \mathrm{in}^{2}\right)$ of the magnesia chromite and graphite refractory bricks were prepared by setting in acrylic resin. The original surfaces (hot and cold faces) of the freeze lining samples were preserved during sample preparation, thus the length of the freeze lining samples was not $5.08 \mathrm{~cm}$ (as directed by the ASTM standard), but the as-received thickness of 10 and $8 \mathrm{~cm}$ for the Mortimer and Polokwane specimens. While the permeability was measured through all the composite layers of the Polokwane freeze lining, the Mortimer freeze lining sample was sectioned into its respective layers (Figure 5) whereby the respective contributions of each layer towards the overall permeability could be measured. The hot face, crystalline layers, and cold face had thicknesses of approximately 3,5 , and $2 \mathrm{~cm}$ respectively. The outer surface of the acrylic resin of each layer was sealed with a layer of silicone gasket sealant so that their individual permeabilities could be measured and the harmonic-average permeability of the layers in series could be calculated using Equation [7].

A $0.5 \mathrm{slm}$ (standard litres per minute) mass flow controller was used to control the flow rate of nitrogen into the cavity bordering the lower surface of the sample. As these instruments are prone to error, the set flow rate was correlated to the actual flow rate by measuring the gas flow into a graduated cylinder submerged in a water bath.

For the gas permeability measurements, the samples (after being set in resin) were left in a drying oven at $110^{\circ} \mathrm{C}$ overnight

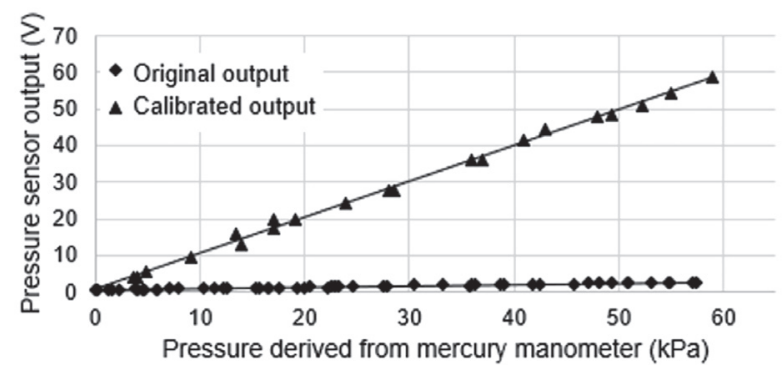

Figure 9-The amplification of the voltage output of the pressure senso
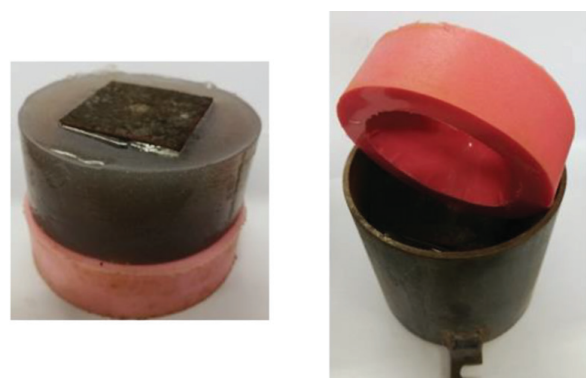

Figure 10-(a) A sample of magnesia-chromite brick set in acrylic resin; (b) the profile of the custom silicone gasket 


\section{An investigation into the permeability of a PGM slag freeze lining to sulphur}

to drive off any moisture. The sample for which the permeability was to be measured was secured between the two silicone gaskets and tightened at a set torque. The flow of nitrogen was increased in increments of $5 \%$ of the maximum flow rate, $0.5 \mathrm{slm}$. An average time of four minutes was allowed for the pressure to stabilize, after which it was assumed that the gas flow rate into the sample was equal to the flow rate out of the sample. The permeability was calculated using Darcy's Law (Equation [6]). The sets of measurements were repeated three times on each sample.

\section{Results and discussion}

\section{Bulk densities and apparent porosities}

The apparent porosities and bulk densities of the samples are summarized in Table I. The bulk densities of the Polokwane and Mortimer cold face layers were similar, and higher than the bulk density of the Mortimer hot face layer. This Mortimer hot face layer had the highest apparent porosity, and the cold face of the Polokwane freeze lining sample the lowest, confirming the macroscopic observations. The magnesia-chromite brick had a lower apparent porosity and higher bulk density than the graphite brick.

\section{Penetration of liquid sulphur into the freeze lining}

SEM-EDS analysis confirmed that liquid sulphur can penetrate into cracks inside the freeze lining at $120^{\circ} \mathrm{C}$ (Figure 11). During operation, cracks inside the freeze lining are expected to form due to thermal shock when level changes occur in the molten bath such as during tapping and downtime of the furnace. The cracks inside the specimens used in the experiments could have been introduced when the $5 \mathrm{~mm}$ hole was drilled. However, the freeze lining inside the smelter most certainly forms cracks as the freeze lining breaks off and re-forms. Thus, the experiment simulated the permeation of sulphur into a crack that formed in a freeze lining. The cracks seem to have propagated along the pores inside the freeze lining.

Although the degree of penetration by sulphur was expected to increase with an increase in temperature, the opposite was observed. Compared to the penetration of sulphur into the freeze lining at $120^{\circ} \mathrm{C}$ (Figure 11), which was a few centimeters deep, there was virtually no penetration of sulphur into cracks of similar width at $180^{\circ} \mathrm{C}$ (Figure 12).

The lack of penetration of sulphur can be explained by the change in dynamic viscosity of liquid sulphur between 120 and $180^{\circ} \mathrm{C}$. The four orders-of-magnitude increase in the dynamic viscosity of sulphur from $9 \times 10^{-2}$ Pa.s to $93000 \times 10^{-2} \mathrm{~Pa} . \mathrm{S}$ between $120^{\circ} \mathrm{C}$ and $187^{\circ} \mathrm{C}$ is shown in Figure 13 (Sofekun et al., 2017). The maximum dynamic viscosity of sulphur at $187^{\circ} \mathrm{C}$ is 52000 times the viscosity of water at $17^{\circ} \mathrm{C}$, and sulphur was too viscous at $180^{\circ} \mathrm{C}$ to penetrate into cracks inside the freeze lining. Any liquid sulphur inside the furnace wall is expected to have a similar dynamic viscosity as the liquid sulphur in the first experiment at $120^{\circ} \mathrm{C}$, due to the viscosity returning to $9 \times 10^{-2}$ Pa.s at temperatures above $280^{\circ} \mathrm{C}$ (Figure 13). Thus, if cracks develop in a freeze lining during operation, they will become filled with sulphur. If these cracks have appropriate orientation
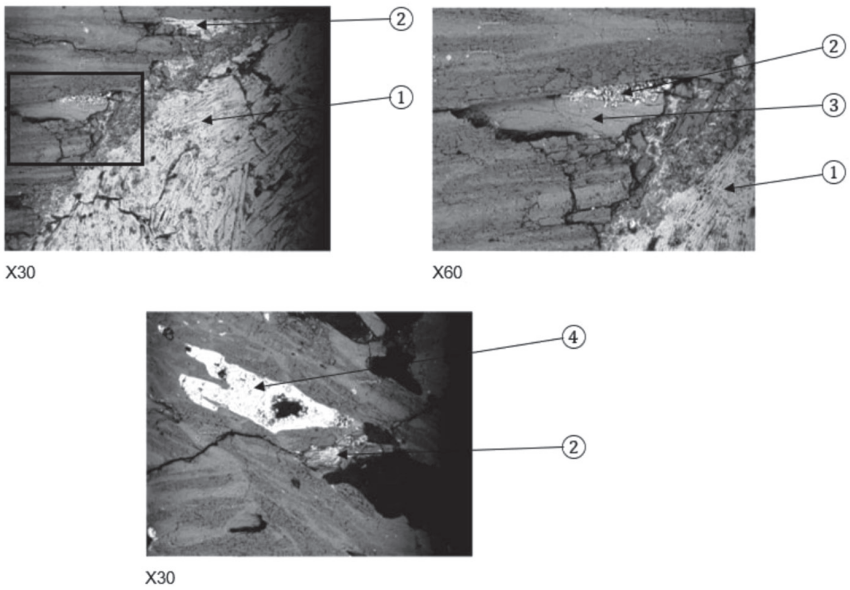

Figure $12-$ No penetration of sulphur into a cracked freeze lining at $180^{\circ} \mathrm{C}$ (1) Primary sulphur inside drilled hole, (2) sulphur that penetrated into freeze lining, (3) iron, (4) entrained matte droplet

Table I

Bulk density and apparent porosity data of the brick and freeze lining samples

\begin{tabular}{|l|c|c|c|}
\hline \multirow{2}{*}{ Sample } & \multicolumn{2}{|c|}{ Bulk density (cm $\left.{ }^{3}\right)$} & \multicolumn{2}{c|}{ Apparent porosity (\%) } \\
\cline { 2 - 4 } & Average & Standard deviation & Average \\
\hline Polokwane Smelter freeze lining: cold face & 2,95 & $\mathrm{~N} / \mathrm{A}$ & 8.0 \\
Mortimer Smelter freeze lining: cold face & 2,92 & 0.12 & 10.8 \\
Mortimer Smelter freeze lining: hot face & 2.42 & 0.04 & 23.2 \\
Magnesia - chromite brick & 3.37 & 0.03 & 1.8 \\
Graphite brick & 1.90 & 0.03 & 1.0 \\
\end{tabular}

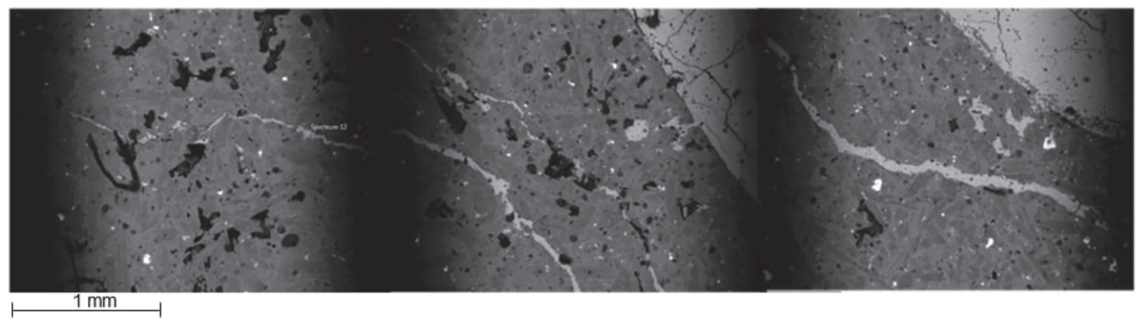

Figure 11-Penetration of sulphur into a cracked freeze lining at $120^{\circ} \mathrm{C}$. The origin of the crack is below the drilled hole (right) and extended to the outer edge of the sample (left) 


\section{An investigation into the permeability of a PGM slag freeze lining to sulphur}

(perpendicular to the hot face) and length, they can facilitate the permeation of sulphur through the layered freeze lining to the graphite block in front of the copper cooler. Sulphidation of the underlying copper coolers will then depend on the resistance of the graphite block to permeation by sulphur.

\section{Gas permeability of a PGM furnace lining}

The magnesia-chromite and graphite bricks have gas permeabilities of 10.0 and $4.85 \mathrm{~cd}$ respectively at a differential pressure of $32 \mathrm{kPa}$ (Figures 14 and 15). The permeability of this graphite brick falls within the range of permeabilities (0.3-42 cd) reported by Eusner and Shapland (1959) for carbon-based materials that are used in blast furnaces. The standard deviations of the permeability measurements of the magnesia-chromite and graphite bricks across the three sets of measurements were 0.15 and $0.03 \mathrm{~cd}$ respectively. This provides confidence that the measurements obtained using the constructed apparatus were reproducible.

The permeabilities of the layers of the Mortimer freeze lining specimen as a function of pressure are shown in Figure 16. The hot face, crystalline layers and cold face had permeabilities of $2.4,2.2$, and $1.8 \mathrm{~cd}$ at a differential pressure $\left(\Delta P_{i}\right)$ of $32 \mathrm{kPa}$. The overall permeability of the composite freeze lining could be calculated as the harmonic-average permeability (described previously), which equalled $1.5 \mathrm{~cd}$ at a total differential pressure $\left(\Delta P_{t}\right)$ of $32 \mathrm{kPa}$ (Figure 16).

The Polokwane and Mortimer freeze lining specimens had permeabilities of 0.8 and $1.5 \mathrm{~cd}$ respectively at $32 \mathrm{kPa}$. The freeze lining specimens therefore had significantly lower permeabilities than the refractory bricks that were tested (Figure 17), with the cold face controlling the overall permeability of the freeze lining (Figure 16). The Polokwane freeze lining specimen had almost

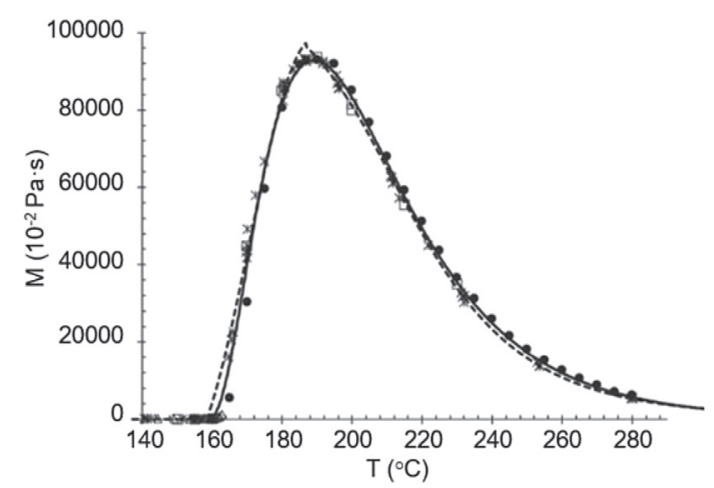

Figure 13-Dynamic viscosity of liquid sulphur as a function of temperature (Sofekun et al., 2017)

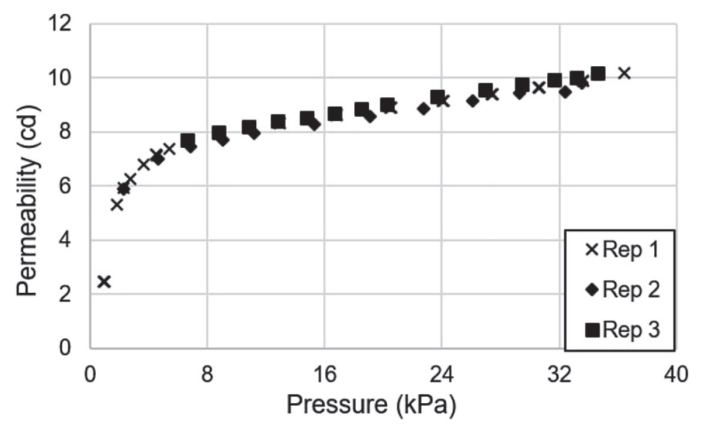

Figure 14-Permeability measurements on the magnesia-chromite brick half the permeability of the Mortimer freeze lining specimen. The higher permeability of the Mortimer freeze lining (2019) is likely due to a combination of a thinner cold face $(2 \mathrm{~cm} v S$. $3 \mathrm{~cm}$ ) and the higher apparent porosity which makes it prone to crack formation. The permeability of the graphite brick was lower than that of the magnesia-chromite brick (4.85 vs. 10.0 cd). This lower permeability is presumably one of the factors that contributed to an increase in the copper cooler campaign lives when graphite bricks replaced magnesia-chromite bricks in the PGM smelter. However, it is also assumed that the significantly higher thermal conductivity of the graphite brick, compared to the magnesia-chromite brick, altered the morphology of the freeze lining, inter alia by the formation of a thicker glassy cold face.

An uncracked PGM slag freeze lining will therefore impede sulphur and other corrosive fluids from permeating through the freeze lining to the refractory lining. The perception that the freeze lining is highly permeable due to its high apparent porosity

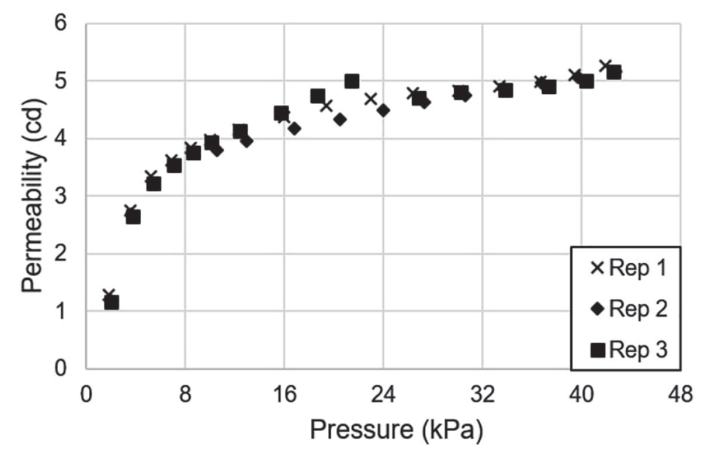

Figure 15-Permeability measurements on the graphite brick

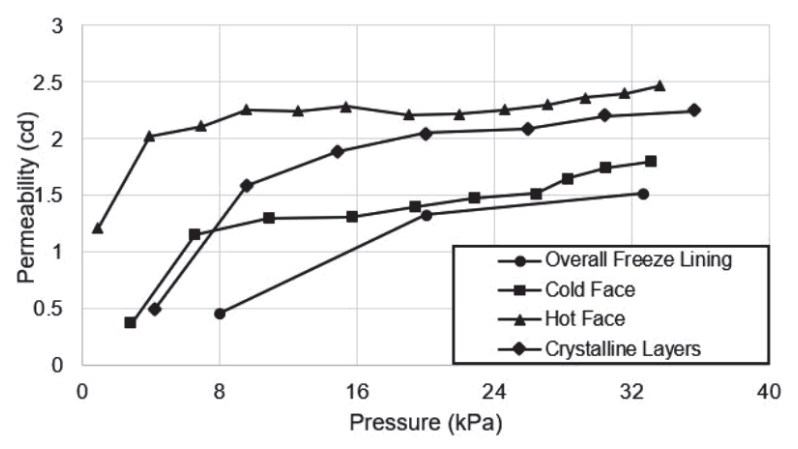

Figure 16-The permeabilities of the layers $\left(K_{i}\right)$ that constituted the Mortimer freeze lining as a function of differential pressure $\left(\Delta P_{i}\right)$, as well as the permeability of the overall freeze lining $\left(K_{\text {avg }}\right)$ as a function of total differential pressure $\left(\Delta P_{t}\right)$

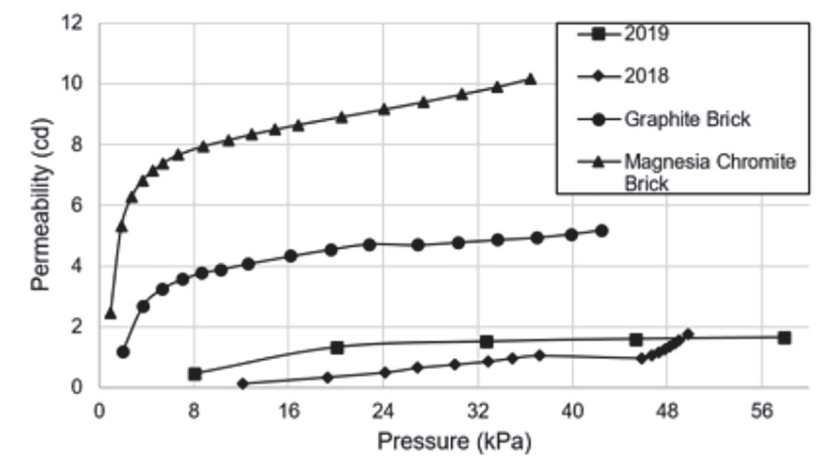

Figure 17-Permeabilities of the refractory bricks, Polokwane (2018) and Mortimer (2019) freeze lining samples 


\section{An investigation into the permeability of a PGM slag freeze lining to sulphur}

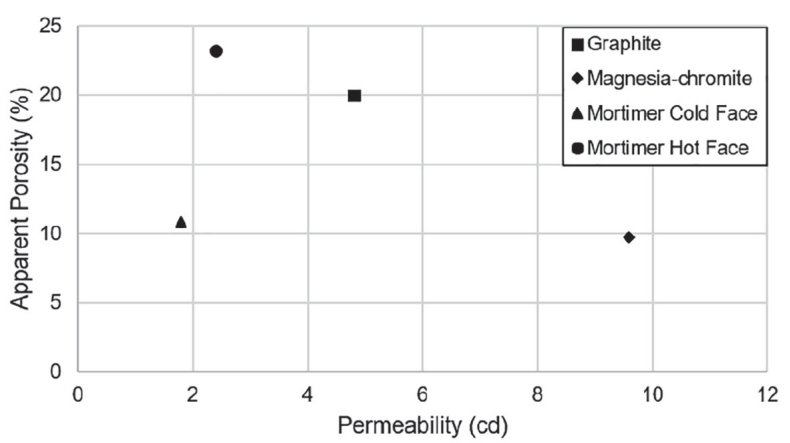

Figure 18-Comparison of the permeabilities of the samples tested and their apparent porosities

at the hot face was shown to be untrue since the hot face had the highest porosity $(23.2 \%)$ but one of the lowest permeabilities $(2.4 \mathrm{~cd})$ compared to the refractory bricks (Figure 18). It is also important to acknowledge that the graphite brick, which has a significantly higher apparent porosity than the evaluated magnesia-chromite brick, has a significantly lower permeability than the magnesia-chromite brick that was previously used in front of the copper coolers.

\section{Conclusions}

> The permeabilities of the freeze lining specimens from Polokwane $(0.8 \mathrm{~cd})$ and Mortimer smelters $(1.5 \mathrm{~cd})$ were lower than those of the graphite $(4.85 \mathrm{~cd})$ and magnesiachromite brick (10 cd) samples.

- The cold face, crystalline layers, and hot face layers of the sample of Mortimer freeze lining had permeabilities of 1.8, 2.2 , and $2.4 \mathrm{~cd}$ respectively. The permeability of the cold face layer controls the overall permeability of the freeze lining.

$>$ Liquid sulphur at $120^{\circ} \mathrm{C}$ is able to permeate through cracks in the slag freeze lining.

> An ideal slag freeze lining would be one that has a thick and crack-free cold face layer, as permeation of sulphur through the freeze lining to the refractory brick would then be minimized.

\section{Acknowledgements}

Anglo American Platinum is thanked for providing the University of Pretoria with the samples used in this project and for permission to publish the findings. The assistance of Dr Robert Cromarty (in the construction and calibration of the permeability test set-up) and Mr Dirk Odendaal (assistance in the laboratory) is also greatly appreciated. Cermalab is acknowledged for providing the University of Pretoria with the ASTM standard for testing the permeability of refractory bricks and for determining the bulk density and apparent porosities of the samples.

\section{References}

Augustyn, A., Bauer, P., Duignan, B., Alison, E., Gregersen, E., McKenna, A., Petruzzello, M., Rafferty, J.P., Ray, M., Rogers, K., Tikkanen, A., Wallenfeldt, J., Zeidan, A., and Zelazko, A. (eds.). 2018. Permeability. https://www.britannica. com/science/permeability-physics [accessed 8 May 2020].

Bello, C. (ed.). 1988. Chemical Periodic Table. 2nd edn. Perma-Chart Science Series, Papertech Marketing Group Inc. Canada.

Berger, B.M. 2010. The importance and testing of density / porosity / permeability / pore size for refractories. Proceedings of Refractories 2010 Conference, Misty
Hills, Muldersdrift, South Africa, 16-17 March 2010. Southern African Institute of Mining and Metallurgy, Johannesburg. pp. 101-116.

CRIVITs, T. 2016. Fundamental studies on the chemical aspects of freeze linings. PhD thesis, University of Queensland, Australia.

Du PreEz, R.C. 2009. Effect of lime additions on the chromium deportment in smelter matte-slag systems. MScEng thesis, University of Stellenbosch, South Africa.

Duncanson, P.L. and Tотн, J.D. 2004. The truths and myths of freeze lining technology for submerged arc furnaces. Proceedings of the Tenth International Ferroalloys Congress, INFACON X, Cape Town, South Africa, 1-4 February 2004. Southern African Institute of Mining and Metallurgy, Johannesburg. pp. 488-499. doi: 0-9584663-5-1

Eusner, G.R. And Shapland, J.T. 1959. Permeability of blast-furnace refractories. Journal of the American Ceramic Society, vol. 42, no. 10. pp. 459-464.

Hundermark, R.J., Mncwango, S.B., de Villiers, L.P.vS., and Nelson, L.R. 2011. The smelting operations of Anglo American's platinum business: an update. Proceedings of the Southern African Pyrometallurgy 2011 International Conference, Misty Hills, Muldersdrift, South Africa, 6-9 March 2011. Jones, R.T. and den Hoed, P. (eds.). Southern African Institute of Mining and Metallurgy, Johannesburg. pp. 295-307.

JAcoBs, M. 2006. Process description and abbreviated history of Anglo Platinum's Waterval Smelter. Proceedings of the Southern African Pyrometallurgy 2006 International conference, Cradle of Humankind, South Africa, 5-8 March 2006. Jones, R.T. (ed.). Southern African Institute of Mining and Metallurgy, Johannesburg. pp. 17-28.

KantZAS, A., Bryan, J., and TAHERI, S. 2015. Harmonic - average permeability. Fundamentals of Fluid Flow in Porous Media. PERM Inc. https://perminc.com/ resources/fundamentals-of-fluid-flow-in-porous-media/chapter-2-the-porousmedium/permeability/harmonic-average-permeability/ [accessed 8 May 2020].

Lyons, J.R. 2008. An estimate of the equilibrium speciation of sulfur vapor over solid sulfur and implications for planetary atmospheres. Journal of Sulfur Chemistry, vol. 29, no. 3. pp. 269-279.

Mabiza, L, Picas, R., Nell, J., Matsetela, B., and Erasmus, G. 2011. Characterisation of $\mathrm{SO}_{2}$ in off-gas at Zimplats Smelter. Proceedings of the Southern African Pyrometallurgy 2011 International Conference, Muldersdrift, South Africa, 6-9 March 2011. Jones, R.T. and den Hoed, P. (eds.). Southern African Institute of Mining and Metallurgy, Johannesburg. pp. 161-172.

NoLET, I. 2014. Tapping of PGM-Ni mattes: an industry survey. Proceedings of the Southern African Furnace Tapping Conference 2014, Muldersdrift, South Africa, 27-29 May 2014. Southern African Institute of Mining and Metallurgy, Johannesburg. pp. 223-232.

Shaw, A., de Villiers, L.P., Hundermark, R.J., Ndlovu, J., Nelson, L.R., Pieterse, B., and McKenzIE, A.D. 2013. Challenges and solutions in PGM furnace operation: High matte temperature and copper cooler corrosion. Journal of the Southern African Institute of Mining and Metallurgy, vol. 113, no. 3. pp. 251-261.

Sofekun, G.O., Evoy, E., Lesage, K.L., Chou, N., and Marriott, R.A. 2017. The rheology of liquid elemental sulfur across the gamma-transition. Journal of Rheology, vol. 62, no. 2. pp. 469-476.

Thethwayo, B.M. and Garbers-Craig, A.M. 2010. Corrosion of copper coolers in PGM smelters. Proceedings of the 4th International Platinum Conference: Platinum in Transition 'Boom or Bust', Rustenburg, South Africa, 11-14 October 2010. Southern African Institute of Mining and Metallurgy, Johannesburg. pp. $187-188$

Theтhwayo, B.M. 2010. Sulphidation of copper coolers in PGM smelters. MSc thesis, University of Pretoria, South Africa.

Thethwayo, B.M. and Garbers-Craig, A.M. 2011. Laboratory scale investigation into the corrosion of copper in a sulphur-containing environment. Corrosion Science, vol. 53. pp. 3068-3074. 